\title{
XXXIX. Experiments on the production of sounds in vapours.--Read at the institute, October 12, 1807
}

\section{Biot}

To cite this article: M. Biot (1809) XXXIX. Experiments on the production of sounds in vapours.-Read at the institute, October 12, 1807, Philosophical Magazine Series 1, 34:138, 277-281, DOI: $10.1080 / 14786440908562962$

To link to this article: http://dx.doi.org/10.1080/14786440908562962

曲 Published online: 18 May 2009.

Submit your article to this journal $₫$

Џll Article views: 2

Q View related articles $\sqsubset$ 
which originate from the brain, and the much greater which branch off in succession from the spine into the adjacent parts ; an arrangement which distributes the source of vitality along the whole frame of the animal.

I am, sir, your most obedient humble servant, John Carr.

Princess Street, Manchester,

Octuber 7, 1849.

XXXIX. Experiments on the Production of Sounds in Vapours. By M. Bior.-Read at the Instilute, Ouober $12,180^{-*}$.

$\mathrm{N}$

UMBERLESs experiments have been made by natural philosophers on the production and propagation of sound in different mediums: they have demonstruted that it neither is produced nor propagated in vacum ; they have examined its transmission through liquid and solid bodies: but no one, to my knowledge, has repeated those experiments in vapours, and yet this research is well adapted to excite curiosity; for in discriminating between the facts which experience has disclosed relative to the constitution of vapours which fill a space, and in applying to them mathematical principles, the foundations of the establinhed laws of the mimnte vibrations of elastic fuids, it is evident, that absolutely no sound should be poduced in them.

In fact, it is prover hy the experiments of Deluc, Saussure, and Dalton, that the quantity of the vapours of water, or of any other liqud formed in vacuum, depends alone on the dimensions of the sface and on the comperature: in short, if this vapou has an elastic force, capable of sustaining the manomcter at a certain height, and if it be slowly compressed, so that it may rcculy less space, the elastic force will not increase by this ci, mpression, as would happen to a permanent gas; but part of the vapour will assume the liquid state, without which the manometer varies, and it becomes stationary only as it aerees with the new limits to which the spice is rednced. But the contrary will happen if the space is increased instcad of being diminished; a fresh quantry of vap ar will arse to fill it, without producing any change etther in the elastic force or in the manometer. These results are perfecty es'ablished by philosophers, whom I shall hereafier quote, and we may with great ease be convinced of their accuracy. For the

* From Mémoires de la Société d'Arcueil. 
purpose it is sufficient to introduce into a barometer a sinall quantity of any liquid, and to measure the height at which the mercury stops after being depressed by the elastic force of the vapour that is formed. If then the external surface of the mercury is either elevated or depressed, the interior column will rise or fall in the tube precisely in the same proportion; and according as the space which remains in the top of the tube is diminished or increased, a part of the vapour will precipitate itself or rise afresh; but the temperature remaining the same, no variation will appear in the elastic force.

Now, supposing a sonorous body vibrates in a similar medium, each of its oscillations will diminish, in one sense, the space, and will augment it in the other. Thus on one side there will be a suall quantity of vapour which will pass into the liquid state; and on the contrary, a small quantity of liquid that will assume the state of vapour. These condeusations and expansions will take place very near the sonorous body, in the immediate vicinitv of the vibrations; but they will not be further extended. Thus the impulse will not be exerted on the remaining fluid mass, and consequently the sound will not be transmitted. Now let us suppose that the sonorous body, compressing the vapour by its rapid vibrations, mechanically disengiges from it a certain quantity of heat. This supposition is not at all improbable, for it is well known that much heat is emitted during the condensation of vapour. For instance, the vapour of water, according to the experiments of Watt, sets at liberty, whilst passing from the aëriform to the fluid state, heat sufficient to raise the mass of water thus formed to 525 of the thermometer centesimal. Paying attention to this circumstance, the effects of a sonorous body on vapour are not the same; the compressed portions mainain the state of an elastic fluid in spite of the diminution of space, on account of the liberated heat, which gives them a momentary increase of power. On the contrary, in the expanded portion, the decrease of temperature prevents a new formation of vapour, and occasions a diminution of elasticity. The phænomena which are produced near the sonorous body, are, then, of the same nature as if the vapour became a permanent gas. They consist of increments and diminution of elasticity successively and momentarily produced, spreading their effects from strata to strata through the whole fluid mass, so as to permit the production and propagation of sound.

Experiments, therefore on the production of sound in vapour 
vapour are verv proper to decide the question, whether heat is really disengaged by the effect of the vibrations of sonorous bodies in an aërform medium, as, we see generaily takes place on all rapid compressinns. To this test, and it is a decisive test, may the ingenious idea of $M$. La Place be submitted, by which he has found means to reconcile the mathematical theory of the propication of sound in air with experimental results, in which the disengaged heat was duly attended to; for, if the cffect which lie infers does not really take place, the vibrations of sonorous bodies in vapours ought absolutely to produce no some; and if any is produced, it can be considered only ats the sole effect of the liberated heat.

Influenced by this motive, I made on the subject some experiments which were attended with evident success; and I have since repeated them in a more complete manuer at Arcutil with my friend Amédéf Férthollet. M. Berthollet and M. La Place were presem at those experiments, and fully satisfied themselves of the truth of the facts which I proceed to relate.

We used a glass balloun of the capacity of 36 litres; its orifice was closed by a perfectly tight siop-cock, so that an exhaustion might be make, and preserved good. To this another might be connected, that, by pouring a liquid into the intermediate hollow and clusing bolls cocks, this portion of liquid might be introduced into the interior of the balloon without anv danger of admining the least external atr. Lastly, the sonorous body was a simall bell suspendod within by a very fine cord tied to the lower stop cock.

First, a vacumin was formed in the nuterior it the apparatus with the greatest care, and erea the Jargest part of the hvgrometric water of the balloun, which was dways very dry, was alstracted. Then boldug the balloon by the stop-cock, the bell was set in motum, satistying ourselves that the blows fell with force on the me:al; and whatever attention was naid, or however near we were to the balloon itself, it was absolutely imposstble to distinguish any percepuble sound: therefore sound is not sensible in the vacuum; a fact constantly in harmony with the experiments of Hawksbee, and of all other natural philos phers.

Then proceeding as I have described, a small quantity of water was introduced, part of which rose in vapiur. immediately the sound became percepuble; yet the density of this vapour was very little, the temperature heing uo inore iban 19 of the thermometer centesmal: to incredse it an excess of water was added, and the balloun was carried into 
a green-house (une etuve), the temperature of which was $46^{\circ}$ : then the sound becanie very sensible; it was heard by us, without inclining ourselves to the balloon, and even through the door without the green-house:- there yet remained in the balloon water in the liquid state: thus there is no doubt of the production and propagation of sound in watery vaponr.

When the balloon was taken out of the green-house its temperature quickly fell : of course the principal part of the vapour raised by the ineans of temperature was precipitated; the sound likewise appeared very sensibly diminished. Without making any change in the apparatus, the same quantity of alcohol as water was introduced. Water considered as $1^{\circ}$, the specitic gravity of this alcohol was 0.823 . The vapour formed of this mixture was necessarily of greater density and elasticity than that of water at the same temperature; the sound too was much more sensible, it was beard from the extremities of the rooms forming the Museum of Natural History. Thus is sound also produced and propagated in the vapour of alcohol.

For our conclusive experiment we made trial of the vapour of ether : it was peculiarly interesting to us cin account of its great density and elastic force, which are known to be very considerable; two circumstances which should increase the intensity of the sound. The balloon was first dried, as humidity diminishes the tension of the ether; then the atmospheric air was freely allowed to enter until ain equilibrium was produced with the external pressure, which was 0.7613 ; the balloon was taken into a lowg alley in the garden, and the sound of the bell was found to be sensible even to the distance of $145^{\mathrm{m}}$; beyond this it became so weak that the sensation was not sufinciently distinct: The temperature was $17 \cdot 75$. Having measured by this experiment the intunsity of sound produced in atmospheric air, a racuum was again made in the ballon, and more sulphuric ether was miroduced than the temperature could raise in vapour. The specific gravity of this ether was 0.759 ; the thastic force of its vapour, measured by being introdaced under a barimeter purged of air, was $0^{\text {m }} 35.49$ at the ternperature of 17.56 . The balloon being thus filled with vapour as renovel to the place where the preceding riment had been nialie, and the sound was ascertained nille a: the distance of $131^{\mathrm{m}} \cdot 5$, a convincing proof . - an an a have proved that this can only be

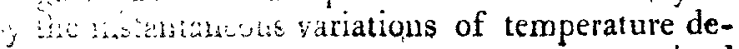
termined 
termined by the vibrations. Hence it is evident that this cause is the true one; and according to the beautiful remark of $\mathbf{M}$. La Place, there is an absolute necessity to pay attention to it in the mathematical theory of the propagation of sound, although it camnot be veriffed by means of the thermometer, as it is an instrument not to be affected by successive and momentary variations of heat, similar to the barometer, which does not show the instantaneous changes of the elastic force, the cause of sound, and yet the reality of those changes is acknowledged by the whole world.

XL. Observations on the remarkalle Efficacy of Carrots, under a new Mode of Application, in the Cure of Ulcers and Sores. By Mr. RiCHARD WALKER*.

T ThE carrot poultice is an application which has been long in use to correct the disposition and improve the discharge of the putrid or scorbutic ulcer.

The manner in which it is usually applied, is by grating, or scraping the carrots fine, and laying them on raw.

I have lately had reason to believe, that the effects of it may be considerably increased, by varying the mode of application.

Several cases occurred in the Radcliffe infirmary, during the summer and beginning of the winter last year, of the true, malignant, scorbutic ulcer.

All the common methods of freatment were adopted, and of course the carrot poultice was not omitted.

The inefficacy of it however was too evident.

In consequence therefore of the ill success attending this practice, several of the cases termmating fatally, and as fresh instances were continually accurrung, the following change was at length tried, in the use of this remedy.

The carrots being previously cleaned by scrapiug and washing, were split and boiled till quite tender, in a small quantity of water; the liquor was then strained, or poured off, and the carrots beaten in a mortar, to the consistence of an uniform soft moist pulp.

The ulcers were first washed clean with the liquor rather warm, in which the carrots had been boiled, sometimes fomented with it, and the carrot poultice being previously spread ready, that the sore might be as little exposed to the air as possible, applied cold.

This was repeated night and morning, and oftener when

* Communicated by the Author.

the 